\title{
Capacidades de modulación y plasticidad funcional de los mecanismos de captura de alimento en Atherinopsinae sudamericanos (Teleostei, Atherinidae)*
}

\author{
EDUARDO DE LA HOZ U., CECILIA CANCINO A. y ENRIQUETA OJEDA C. \\ Laboratorio de Zoología, Instituto de Biología \\ Universidad Católica de Valparaíso \\ Casilla 2950, Valparaíso, Chile
}

RESUMEN. Se describe y compara los diseños estructurales bucales en diferentes especies pertenecientes a dos grupos de géneros de Atherinopsinae, en relación a las características y potencialidades de variabilidad de sus mecanismos de protrusión premaxilar y mordida premaxilar.

El grupo de especies de los géneros Cauque y Austromenidia posee un esquema estructural de huesos, músculos y ligamentos, que determina una gran magnitud de protrusión y una gran capacidad de mordida, en diferentes posiciones de mandíbula y grados de protrusión. Análisis electromiográficos de la actividad de los fascículos $\mathrm{A}_{1}$ y $\mathrm{A}_{3}$ del músculo aductor mandibular y filmaciones durante distintos eventos de captura de presas, demuestran la existencia de gran plasticidad funcional del mecanismo de mordida, capacidad manifestada por diversos grados de sincronización y duración de la actividad entre ambos músculos.

El esquema estructural de Basilichthys, en cambio, determina que estos mecanismos se presenten mucho más restringidos y con un patrón neuromuscular bastante estereotipado, con sólo una pequeña capacidad de variación en la duración de la actividad muscular.

Palabras claves: Atheriniformes, mecanismos alimentarios, morfología funcional.

\section{The capacities of modulation and functional plasticity of the prey capture mechanisms in South-American Atherinopsinae (Teleostei, Atherinidae)}

\begin{abstract}
The design of the buccal structures of species belonging to two genus-groups of Atherinopsinae are described and compared, related to the characteristics and variation potentiality of their mechanisms of premaxillary protrusion and bite.

The species of the Cauque-Austromenidia group have a structural pattern of bones, muscles and ligaments, that determine a large amount of protrusion, and a great capacity of biting. Their premaxillary bite is realized at different jaw positions, as well as degrees of protrusion. Electromyographic analyses of the fascicles $\mathrm{A}_{1} \mathrm{y}_{3}$ of the muscle adductor mandibulae, and film recording during different prey-capture events, show a great plasticity in the biting mechanism. This plasticity is revealed by the di verse degrees of activity syncronism and tirning between muscles.

The structural design of Basilichthys species, determine limited mechanisms with a stereotyped neuromuscular attern, which presents only a small variation capacity in the activity timing, if compared to the Cauque-Austromenidia group.
\end{abstract}

Key words: Atheriniformes, feeding mechanism, functional morphology.

$*$

Trabajo financiado por Proyecto FONDECYT N ${ }^{\circ} 721 / 92$. 


\section{INTRODUCCION}

Los estudios de la relación entre la forma de las estructuras y la realización de una actividad específica, han sido de fundamental importancia en la comprensión del diseño en relación a las demandas impuestas por el medio (Dullemeijer, 1974; Dullemeijer y Barel 1977).

$\mathrm{El}$ análisis de las relaciones espaciales entre componentes estructurales que ejecutan actividades específicas, permite entender el disefto no sólo como una relación forma-función, sino también como un compromiso entre elementos que tienen demandas de construcción diferentes, pero que forman una totalidad estructural coherente (Barel, 1983, 1984; Dullemeijer, 1974; Otten, 1982). Este enfoque lleva implícito el análisis de la compatibilidad de funciones.

En peces, estas investigaciones se han centrado principalmente en el análisis de los mecanismos de captura e ingestión de alimentos, que han permitido entender el significado de adaptaciones estructurales y funcionales en relación a especializaciones tróficas (Anker, 1978; Laudery Liem, 1981; Liem, 1979,1980; Osse, 1969; Otten, 1982; Sibbing, 1982).

Trabajos realizados en Atherinopsinae sudamericanos han permitido constatar la existencia de dos sistemas mecánicos en la captura de presas: una protrusión premaxilar y una acción de mordida utilizando movimientos del premaxilar (De la Hoz, 1994a, 1994b; De la Hoz y Aldunate, 1994; De la Hoz y Vial, 1988, 1994). Las dos actividades son realizadas por los mismos elementos estructurales y pueden presentar características diferentes en distintas especies y géneros.

Este estudio tiene como objetIvos determinar el grado de compatibilidad estructural y funcional de los mecanismos de protrusión y mordida premaxilar, comparando las potencialidades de ejecución de cada uno de ellos y su variabilidad en distintas especies. de los géneros Cauque, Austromenidia y Basilichthys.

\section{MATERIALES Y METODOS}

Los datos estructurales fueron obtenidos de especímenes de las siguientes especies:

- Cauque brevianalis (Günther, 1880). 25 ejempla- res, con longitudes estándar (LS) entre 73 y $125 \mathrm{~mm}$, recolectados en el Estero Quintero (Valparaíso), Estero Laguna Verde (Valparaíso), Estero Pachingo (Tongoy, IV Región) y Estero Perales (VIII Región).

-Cauque mauleanum (Steindachner, 1896). 10 ejemplares, entre 207 y $290 \mathrm{~mm}$ de LS, recolectados en el Lago Llanquihue y Lago Huillinco (X Región).

- Austromenidia regia (Humboldt, 1821). 12 especímenes, entre 92 y $139 \mathrm{~mm}$ de LS, provenientes de la Bahía de Valparaíso.

- Basilichthys semotilus (Cope, 1874). 25 ejemplares, con LS entre 77 y $110 \mathrm{~mm}$, recolectados en el Río Loa (II Región).

- Basilichthys microlepidotus (Jenyns, 1842). 30 ejemplares, entre 75 y $142 \mathrm{~mm}$ de LS, provenientes del Estero Limache (V Región).

- Basilichthys australis (Eigenmann, 1927). 20 especímenes, con LS entre 98 y $150 \mathrm{~mm}$, recolectados en el Río Maule (VII Región) y Río Bío-Bío (VIII Región).

Algunos especímenes de cada especie fueron tratados para diafanizado y tinción de huesos y cartílagos (Dingerkus y Uhler, 1977) y el resto fue conservado en formalina al $10 \%$ y utilizado para observaciones de músculos y ligamentos.

Se usó un microscopio estereoscópico Wild M7, provisto de cámara lúcida, para la confección de figuras y obtención de datos estructurales.

Para la descripción de las figuras se utilizaron las siguientes abreviaturas:

$\mathrm{A}_{1}, \mathrm{~A}_{2}, \mathrm{~A}_{3}, \mathrm{~A}_{\mathrm{w}}$ : fascículos del músculo aductor madibular. ar-an: articular-angular. c: cuadrado. caros: cartílago rostral. d: dentario. entp: entopterigoides. et lat: etmoides lateral. f: frontal. L1: ligamento al maxilar. L2: conexión tendinosa a la mandíbula. Lc: ligamento al lacrimal. Lp: Ligamento primordial. Lprm: ligamento premaxilomaxilar. met: mesetmoides. m.dil.op: músculo dilatador del opérculo. m.le.hm: músculo elevador del hiomandibular. m.le.op: músculo elevador del opercular. mx. maxilar. pl: palatino. pmx: premaxilar. rar: retroarticular. t $\mathrm{A}_{1}$. tendón del fascículo $\mathrm{A}_{1}$ del músculo aductor mandibular. $\mathrm{tA}_{3}$ : tendón del fascículo $\mathrm{A}_{3}$ del músculo aductor mandibular. vo: vomer.

Ejemplares de Cauque brevianalis y Basilichthys microlepidotus fueron mantenidos en acuarios para la obtención de datos electromiográficos y filmaciones durante eventos de captura de presas. 
La actividad muscular se registró utilizando electrodos de cobre de $0.1 \mathrm{~mm}$ de diámetro, conectados a amplificadores diferenciales Tektronix AM 502, calibrados con una ganancia de $2 * 10^{4}$ y una banda entre 300 y $3000 \mathrm{~Hz}$. Los datos electromiográficos fueron almacenados y analizados en un computador provisto de una tarjeta de adquisición de datos ATMIO 16 y software LabWindows.

Simultáneas a los datos electromiográficos, se realizaron filmaciones con una cámara de video Panasonic Digital 5000, a una velocidad de 60 imágenes por segundo, y una videograbadora Sony Umatic VO-4000. La sincronización de las imágenes con las señ.ales obtenidas de la electromiografia, se logró utilizando un LED con frecuencia de $2 \mathrm{~Hz}$, generado por el computador.

Los especímenes fueron anestesiados con MS 222, para la implantación de los electrodos y, luego de un período de 2 a 3 días para el acostumbramiento a situaciones de alta luminosidad momentánea, fueron alimentados con Tubifex ofrecidos de diferentes maneras.

\section{RESULTADOS Y DISCUSION}

\section{Aspectos estructurales del aparato bucal}

\section{Osteología}

Las piezas esqueléticas óseas que conforman el aparato bucal (maxilar, premaxilar, mandíbula y la zona anterior del suspensorio), se presentan configurando dos esquemas estructurales distintos en los diferentes géneros estudiados, como consecuencia de distintos tamaftos, proporciones y relaciones entre ellas.

\section{Esquema estructural de Cauque y Austromenidia} (Figs. 1 a 3).

Mandíbula con diseño de triángulo isósceles, caracterizada por un gran desarrollo de la lámina dorsal posterior del dentario; los bordes dorsales posterior y anterior, aproximadamente de la misma magnitud y mayores que los 2/3 de la longitud de la mandíbula; borde anterior notoriamente cóncavo. Los dientes ocupan menos de la mitad anterior del borde curvo

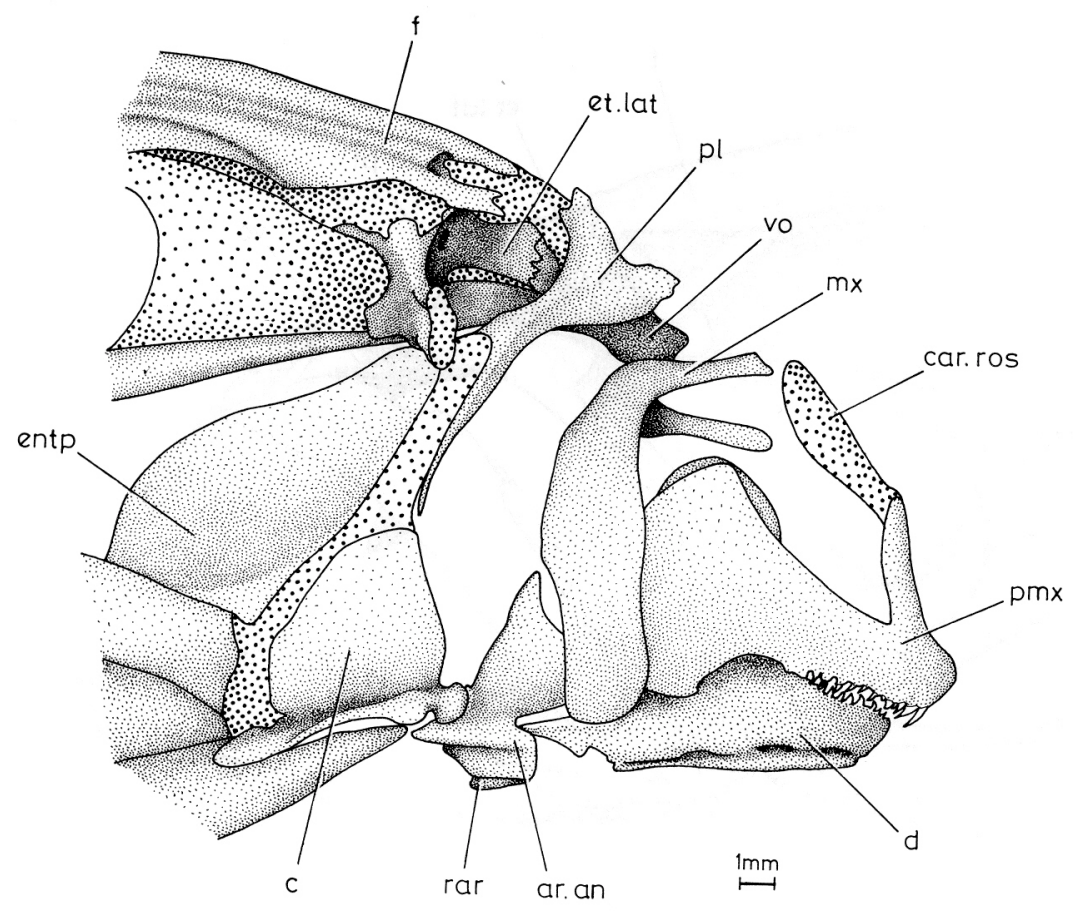

Figura 1. Vista lateral de la región bucal de Cauque mauleanum, en posición ventral de máxima mordida. Fueron removidos el nasal y los infraorbitales. El punteado más grueso indica zonas cartilaginosas. 


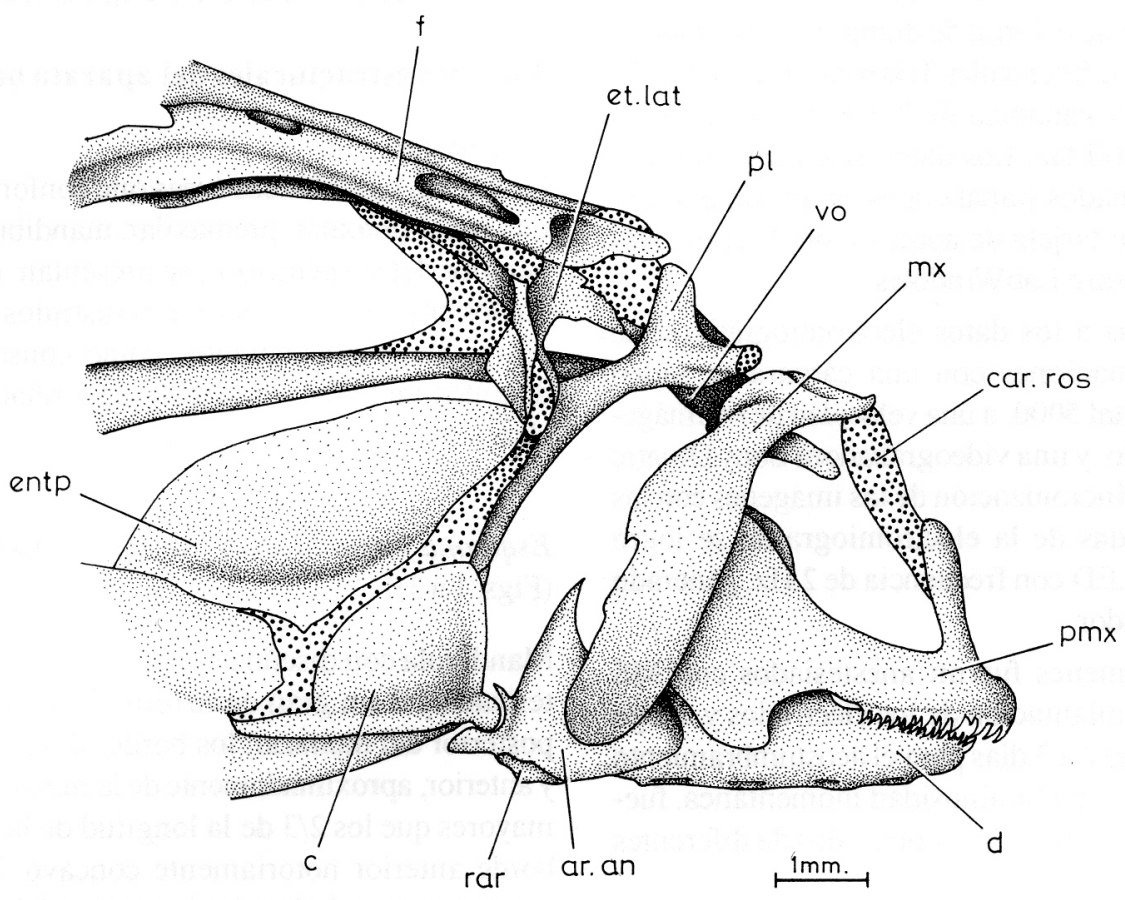

Figura 2. Vista lateral de la región bucal de Cauque brevianalis, en posición ventral de máxima mordida. Fueron removidos el nasal y los infraorbitales.

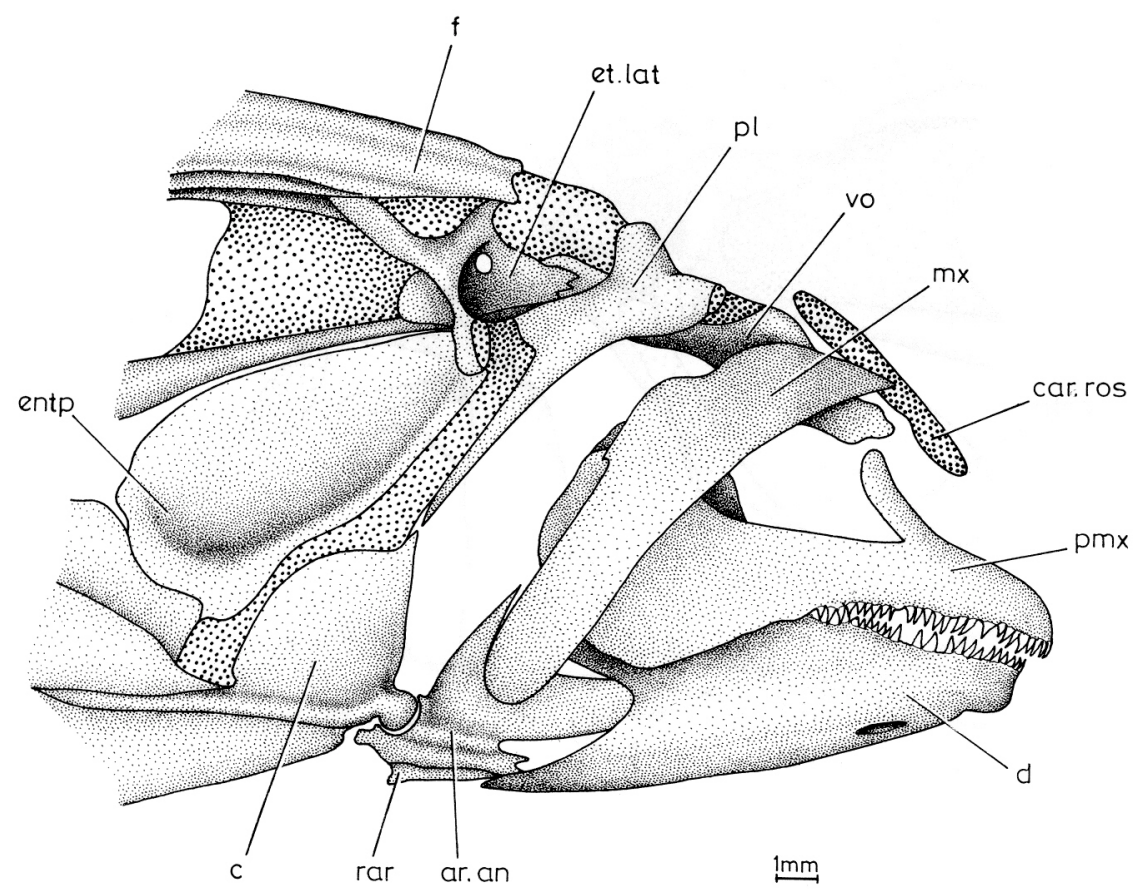

Figura 3. Vista lateral de la región bucal de Austromenidia regia, en posición ventral de máxima mordida. Fueron removidos el nasal y los infraorbitales. 
del dentario (Fig. 7). Una configuración semejante se encuentra en Odontesthes bonariensis (De la Hoz y Vial, 1994).

Maxilar con una cabeza proximal bien desarrollada, que articula con el neurocráneo a través de un menisco cartilaginoso, lo que le permite movimientos de rotación y deslizamiento respecto de la zona etmovomeriana; con un proceso premaxilar interno de tamaño semejante al proceso anterior externo (Fig. 7). Brazo maxilar laminar, con una fuerte escotadura en aproximadamente la mitad de su borde posterior, para inserción del sistema de ligamentos. Desde la superficie interna del extremo distal se origina un fuerte y largo ligamento premaxilo-maxilar.

Premaxilar de diseño caracteristico (Fig. 7), con un proceso ascendente largo y angosto, originado en el tercio anterior; extremo distal ensanchado en una placa laminar amplia: relacionado oon el dentario a través de un corto ligamento en el borde dorsal de la placa, y con el maxilar por intermedio de un largo ligamento inserto cerca del borde dorsal entre el proceso ascendente y el extremo posterior. Asociado al cartílago rostral mediante ligamentos que se insertan en el extremo anterior de éste.
La región anterior del suspensorio es alta, quedando el cóndilo artícular del cuadrado a la altura del etmoides lateral en Austromenidia, mientras que en Cauque lo hace a nivel del cuerpo del palatino (Figs. 1 a 3). Palatino con procesos maxilar y etmoidal desarrollados y de dimensiones semejantes; cuerpo relativamente estrecho, prolongado ventralmente en un proceso agudo y algo curvo (Fig. 7), que conforma el borde anterior del suspensorio.

\section{Esquema estructural de Basilichthys}

(Figs. 4 a 6).

A diferencia de los géneros anteriores, la mandíbula en las especies de Basilichthys se distingue por su menor altura, debido al menor desarrollo de la lámina del dentario; borde dorsal anterior de mayor magnitud que el posterior; borde anterior recto, con dientes hasta más allá de la mitad (Fig. 8).

El diseño de los premaxilares también presenta diferencias importantes. No existen procesos ascendentes distintos, sino que la zona proximal está conformada por una amplia lámina, asociada por su borde medial con el cartílago rostral a través de ligamen-

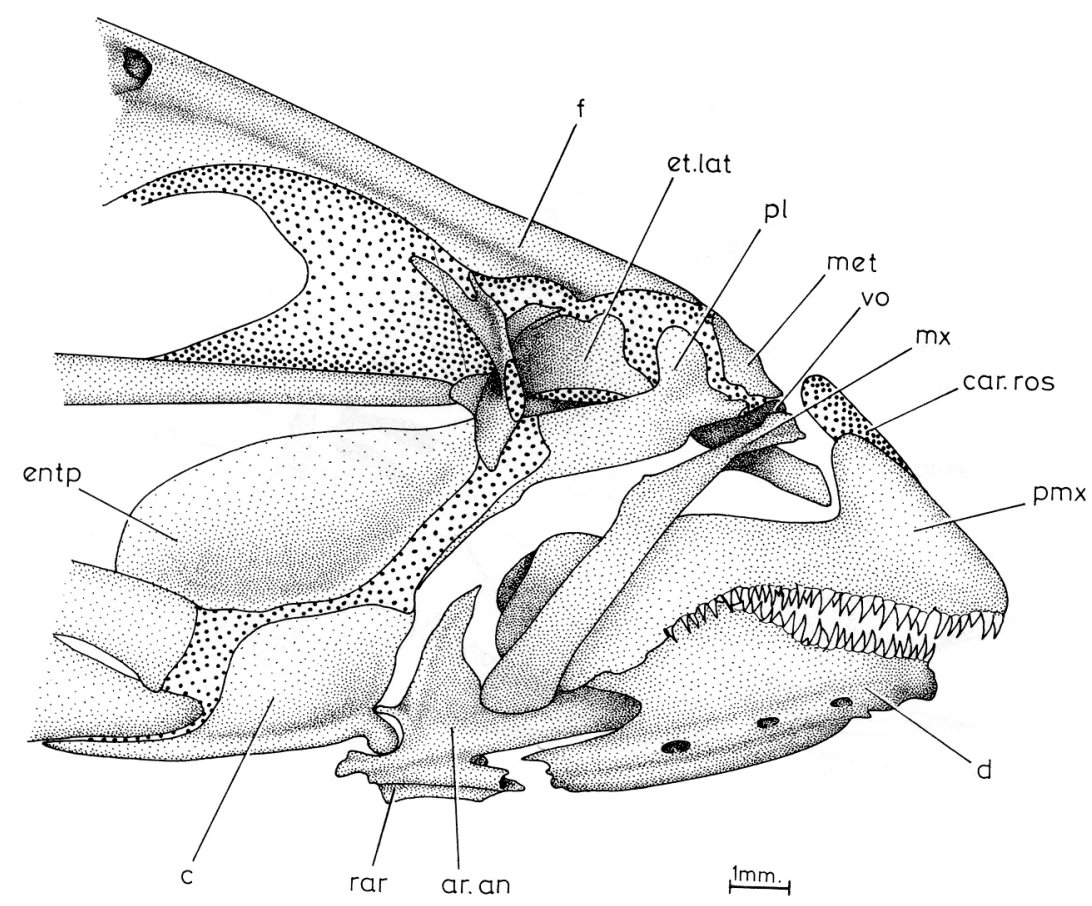

Figura 4. Vista lateral de la región bucal de Basilichthys australis, en posición ventral de máxima mordida. Fueron removidos el nasal y los infraorbitales. 


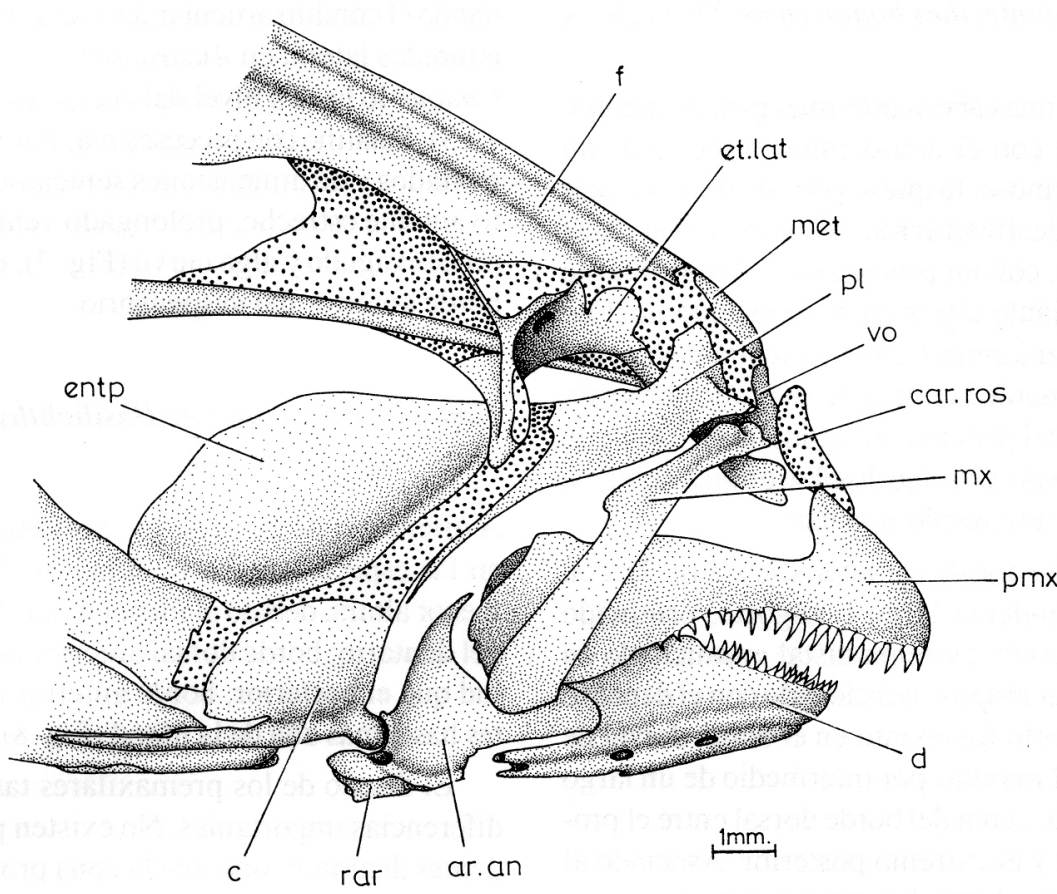

Figura 5. Vista lateral de la región bucal de Basilichthys microlepidotus, en posición ventral de máxima mordida. Fueron removidos el nasal y los infraorbitales.

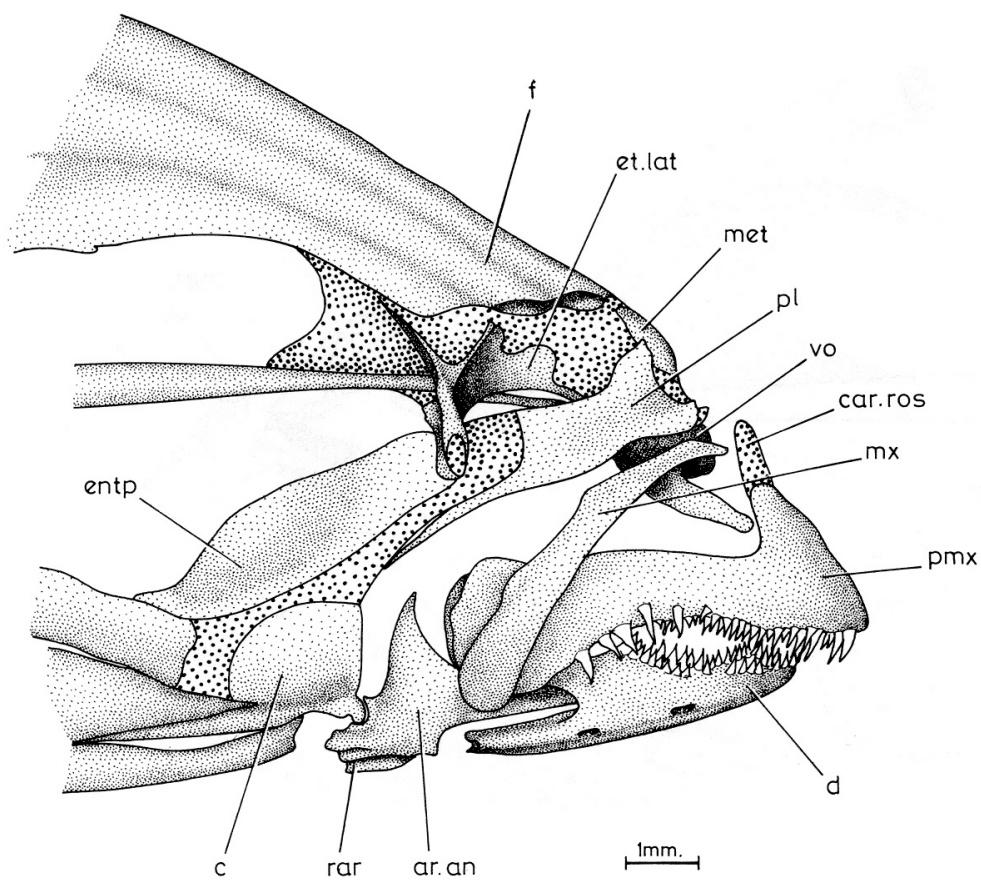

Figura 6. Vista lateral de la región bucal de Basilichthys semotilus, en posición ventral de máxima mordida. Fueron removidos el nasal y los infraorbitales. 
tos; la expansión del extremo posterior es bastante reducida y el borde ventral curvo lleva dientes casi en toda su longitud (Fig. 8).

El maxilar se presenta más delgado, con una cabeza más reducida y con el proceso anterior externo apenas notorio. Brazo maxilar más estrecho y borde posterior con escotadura para el ligamento primordiallocalizada más proximalmente que en Cauque y Austromenidia (Figs. 7 y 8).

El ligamento premaxilo-maxilar mucho más corto que en los géneros anteriores, entre la cara interna del extremo del maxilar y el borde inferior del extremo distal del premaxilar (Figs. 18 a 20).

Cóndilo articular del cuadrado localizado por detrás del nivel del etmoides lateral, lo que determina que el borde anterior del suspensorio se dis- ponga mucho más oblicuo comparado con el grupo anterior (Figs. 4 a 6). Palatino con cuerpo más ancho y con proceso etmoidal más amplio que el proceso maxilar (Fig. 8).

\section{Miología}

(Figs. 9 a 14)

El músculo aductor mandibular en todas las especies consideradas, se encuentra dividido en tres fascículos claramente diferenciables, $\mathrm{A}_{1}, \mathrm{~A}_{2}$ y $\mathrm{A}_{3}$. El fascículo $A_{1}$, el más superficial, se encuentra asociado directamente al maxilar, al lacrimal y a la mandíbula; el fascículo $\mathrm{A}_{2}$ es de dimensiones más reducidas que el anterior y se relaciona con el proceso ascendente del articular-angular de la mandíbula; el fascículo $\mathrm{A}_{3}$, de localización más profunda, se inserta directamente en
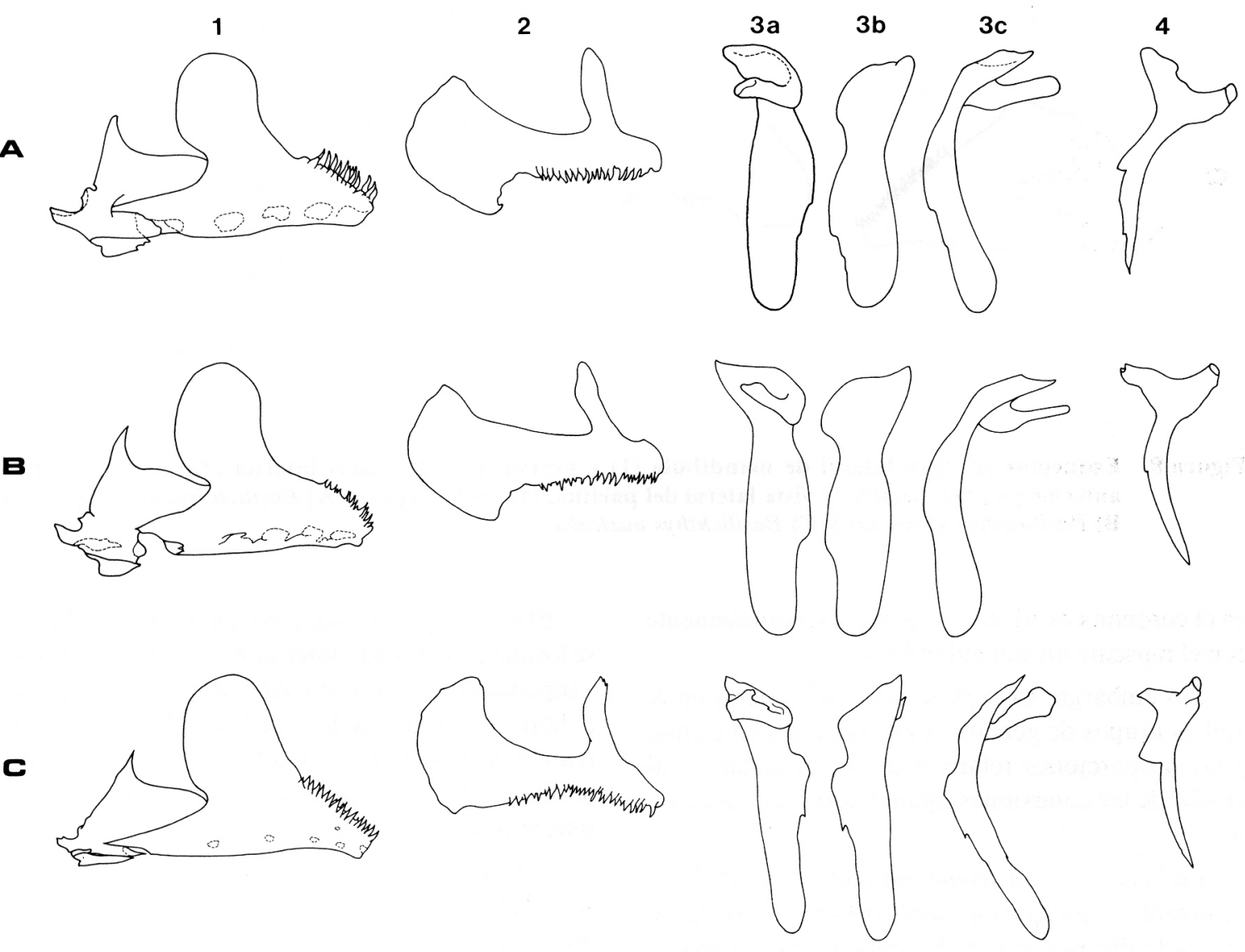

Figura 7. Esquemas en vista lateral de mandíbula (1) y premaxilar (2); vistas interna (3a), externa (3b) y anterior (3c) del maxilar; y vista lateral del palatino (4), en las especies A) Cauque brevianalis, B) Cauque mauleanum y C) Austromenidia regia. 


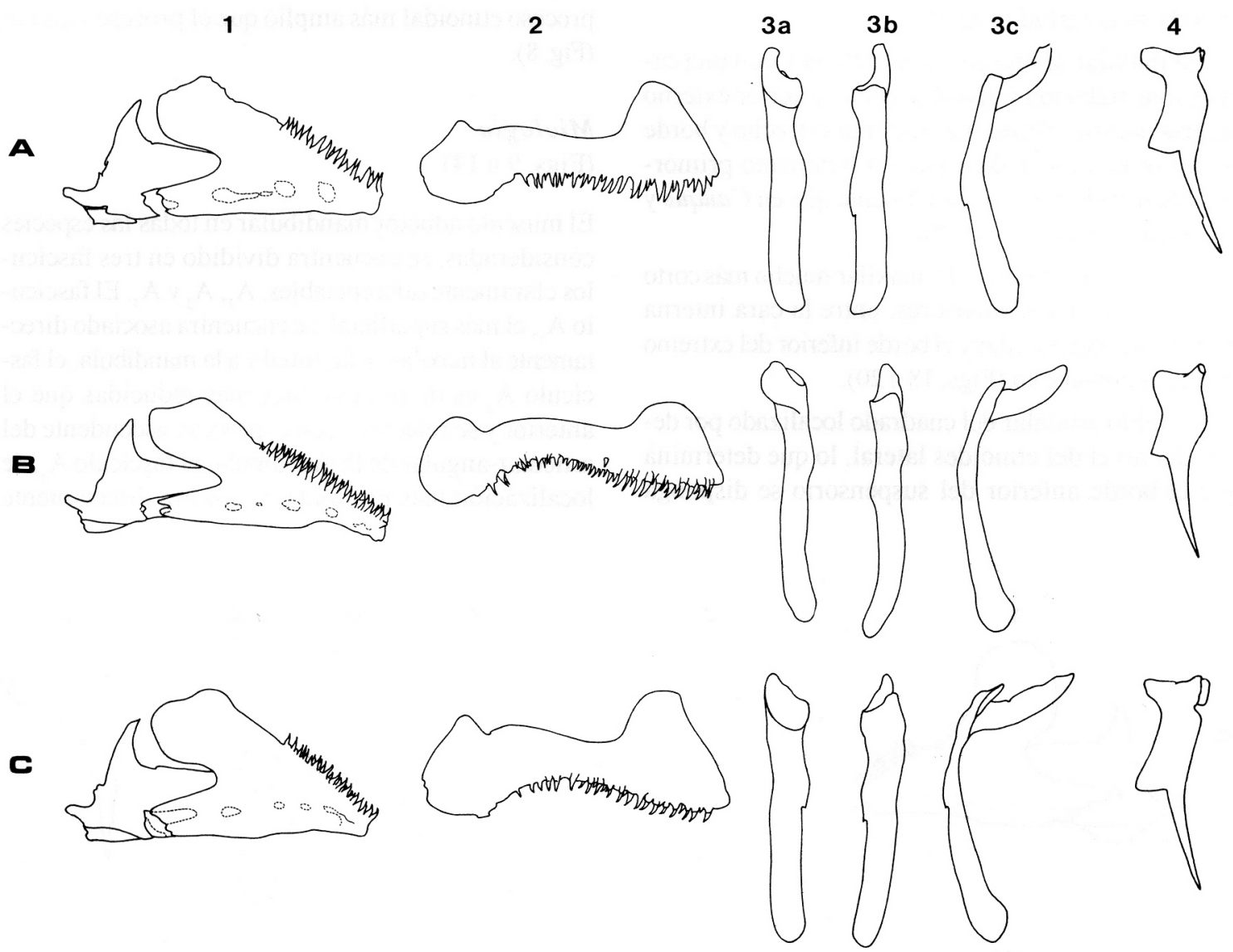

Figura 8. Esquemas en vista lateral de mandíbula (1) y premaxilar (2); vistas interna (3a), externa (3b) y anterior (3c) del maxilar; y vista lateral del palatino (4), en las especies A) Basilichthys microlepidotus, B) Basilichthys semotilus y C) Basilichthys australis.

el coronomeckeliano y se conecta tendinosamente con el músculo intramandibular $\mathrm{A}_{\mathrm{w}}$.

Sin embargo, existen algunas diferencias entre ambos grupos de géneros, especialmente en cuanto a las proporciones relativas de los fascículos y al disefto de las conexiones ligamentosas del fascículo $\mathrm{A}_{1}$.

En Cauque y Austromenidia, el fascículo $\mathrm{A}_{1}$ es de mayor grosor que en Basilichthys, y presenta un grupo de fibras superficiales oblicuas que aparecen por el borde superior del músculo y se insertan en la zona de origen del sistema tendinoso anterior (Figs. 9 a 14).
El origen de este fascículo, en todos los géneros, se localiza en el borde anterior de la rama ascendente y superior de la rama horizontal del preopercular, y en el borde de la espina del cuadrado. La inserción se realiza mediante fibras directas y a través de un importante tendón en el borde posterior y superficie interna adyacente del brazo del maxilar.

$\mathrm{El}$ fascículo $\mathrm{A}_{2}$ del músculo aductor mandibular se reduce a una pequefta lámina de fibras que se originan en el borde dorsal de la espina del cuadrado y se insertan en el borde posterior del proceso dorsal del articular-angular. Cauque y Austromenidia presentan un menor desarrollo de este fascículo (Figs. 9 a 11), comparados con las especies del género 
Basilichthys (Figs. 12 a 14), siendo el de A. regia el de menores dimensiones.

El fascículo $\mathrm{A}_{3}$ es el más interno y se presenta con mayor desarrollo en las especies de Basilichthys. Su región posterior se encuentra dividida en dos partes: una interna, cuyas fibras se originan en el cuadrado, entopterigoides, simpléctico, metapterigoides y en la superficie y borde anterior del hiomandibular, quedando su extremo posterior por debajo del músculo elevador del arco palatino; la parte externa tiene su origen en el borde del preopercular, simpléctico y en algunos casos parte del cuadrado, el extremo posterior pasa por encima del músculo elevador del arco palatino (Figs. 12 a 14).

La inserción del fascículo $\mathrm{A}_{3}$ se realiza mediante un tendón que pasa interno a la mandíbula y llega hasta el coronomeckeliano; la porción dorsal de este tendón se separa anteriormente y se relaciona con las fibras de la parte dorsal del músculo aductor intramandibular $\mathrm{A}_{\mathrm{w}}$ (Figs. 9C a 14C).

El diseño del complejo tendinoso del fascículo Al del músculo aductor mandibular (Figs. 15 a 20), presenta algunas características compartidas por todos los grupos, como la existencia de una conexión tendinosa larga, que se dirige dorsalmente y llega a la superficie interna ventral del hueso lacrimal (Lc), y otro ligamento más corto, que se inserta en la cara externa del articular-angular (L2). No obstante, este sistema tendinoso presenta diferencias importantes entre los dos grupos de especies considerados.

En las especies de Cauque y Austromenidia, aparece otra estructura ligamentosa, que se origina superficialmente en la misma zona de origen de las anteriores (Lc y L2) y se inserta en la escotadura del borde posterior del brazo del maxilar (L1 en Figs. 15 a 17) y que no existe en Basilichthys.

En A. regia (Fig. 17), un grupo de fibras que se originan junto al L1 en la escotadura del borde del maxilar, continúan directas hacia la cara externa del articular-angular insertándose muy cerca del punto de llegada del ligamento L2, constituyendo tipicamente un ligamento primordial (Lp) que relaciona directamente maxilar con mandíbula; en cambio, en las especies de Cauque no existe esta conexión directa.

Todas las especies de Basilichthys presentan un ligamento primordial (Lp), que se origina en la esco-

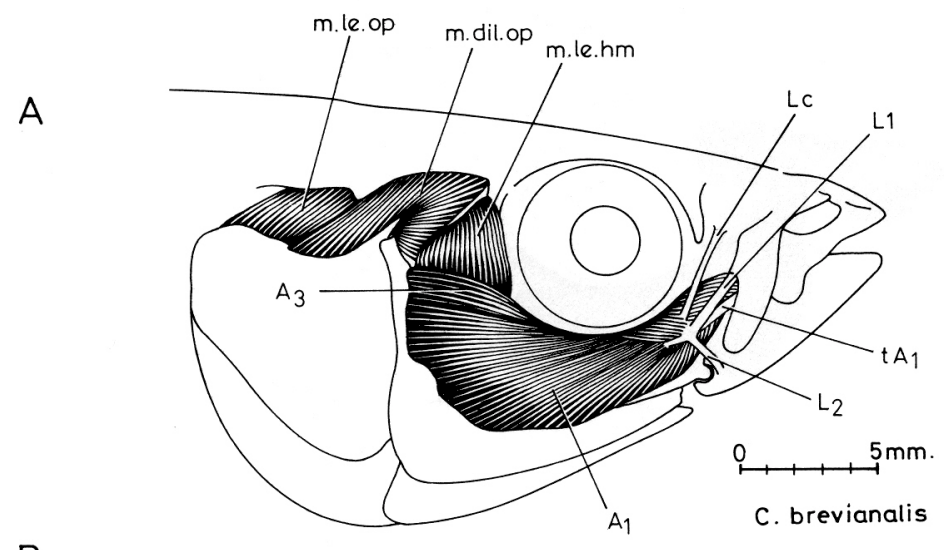

B
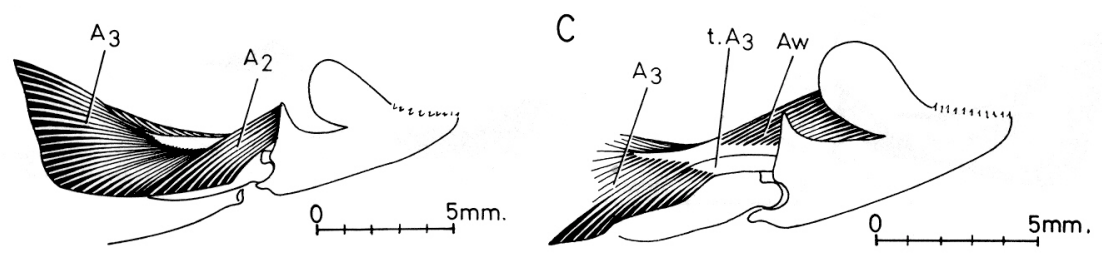

Figura 9. A) Vista lateral de los principales músculos que se relacionan con el mecanismo mandibular en Cauque brevianalis. 8) Vista lateroexterna de la mandíbula derecha, que muestra los fascículos $A_{2}$ y $A_{3}$ del músculo aductor mandibular; fue removido el fascículo $A_{1}$. C) Vista lateroexterna de la mandíbula derecha, mostrando el tendón del $\mathrm{A}_{3}$ y fascículo $\mathrm{A}_{\mathrm{w}}$; fueron removidos los fascículos $\mathrm{A}_{1}$ y $\mathrm{A}_{2}$. 
A

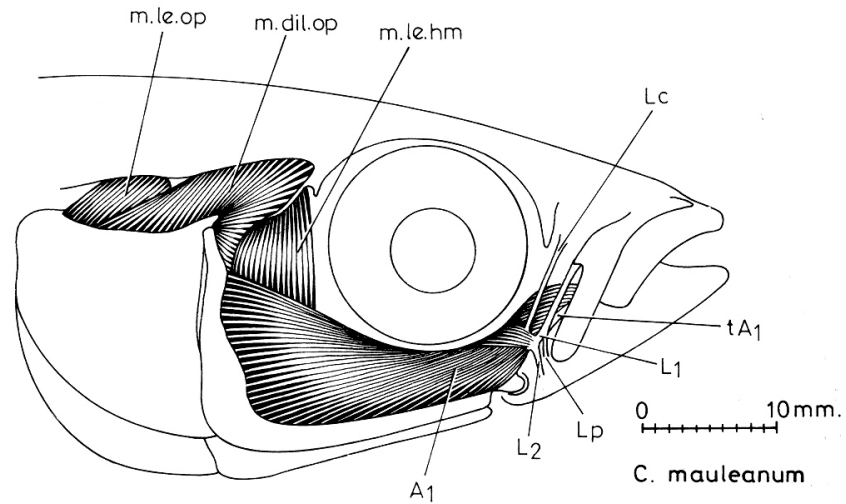

$B$
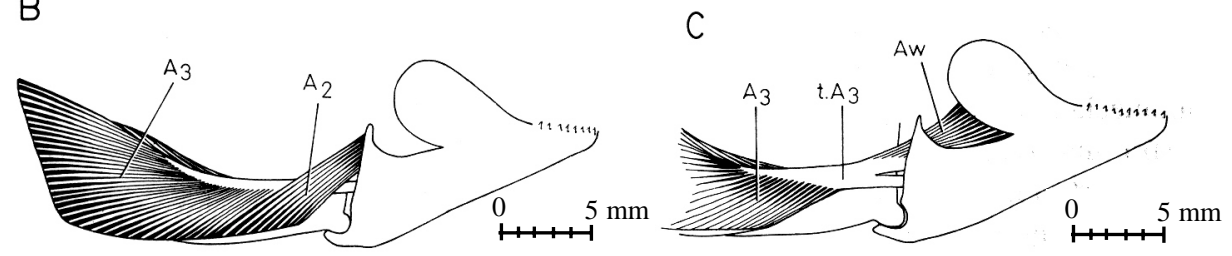

Figura 10. A) Vista lateral de los principales músculos que se relacionan con el mecanismo madibular en Cauque mauleanum. B) Vista lateroexterna de la mandíbula derecha, que muestra, los fascículos $A_{2}$ y $A_{3}$ del músculo aductor mandibular; fue removido el fascículo $A_{1}$. C) Vista lateroexterna de la mandíbula derecha, mostrando el tendón del $A_{3}$ y fascículo $A_{w}$; fueron removidos los fascículos $A_{1}$ y $A_{2}$.

A

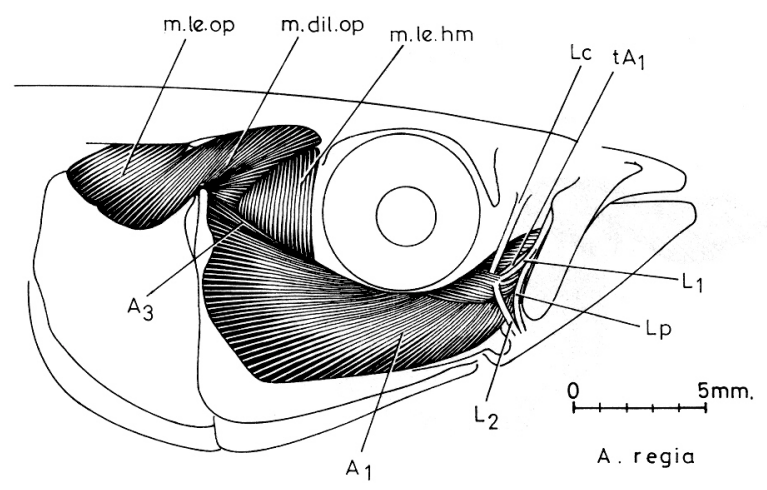

B
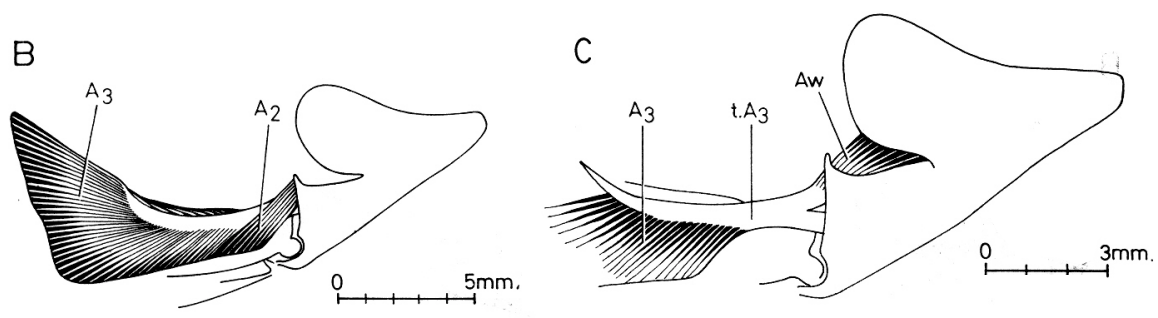

Figura 11. A) Vista lateral de los principales músculos que se relacionan con el mecanismo mandibular en Austromenidia regia. B) Vista lateroexterna de la mandíbula derecha, que muestra los fascículos $\mathrm{A}_{2}$ y $\mathrm{A}_{3}$ del músculo aductor mandibular; fue removido el fascículo $A_{1}$. C) Vista lateroexterna de la mandíbula derecha, mostrando el tendón del $\mathrm{A}_{3}$ y fascículo $\mathrm{A}_{\mathrm{w}}$; fueron removidos los fascículos $\mathrm{A}_{1}$ y $\mathrm{A}_{2}$. 
A

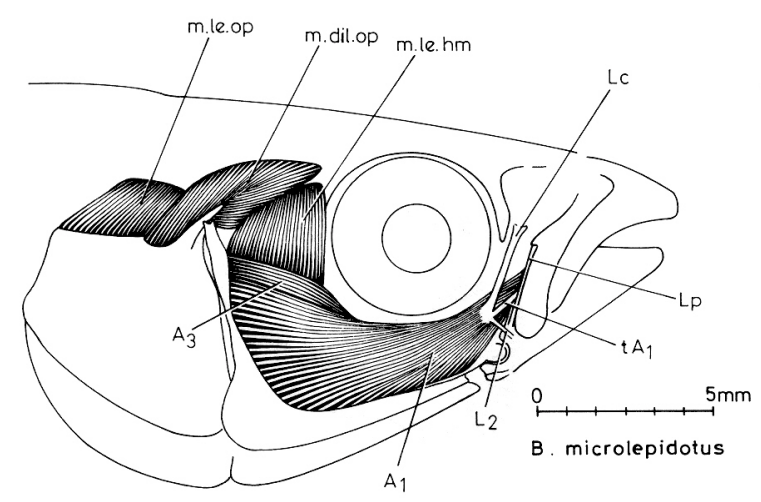

B

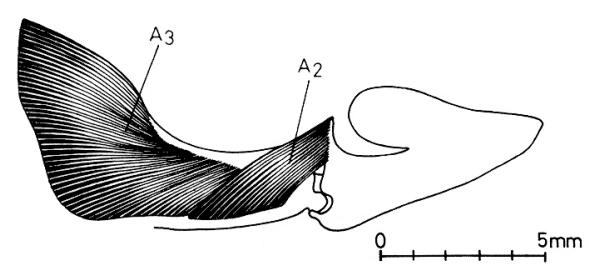

C

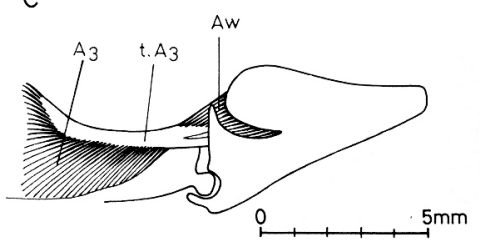

Figura 12. A) Vista lateral de los principales músculos relacionados con el mecanismo mandibular en Basilichtys microlepidotus. B) Vista lateroexterna de la mandíbula derecha, que muestra los fascículos $A_{2}$ y $A_{3}$ del músculo aductor mandibular; fue removido el fascículo $A_{1}$. C) Vista lateroexterna de la mandíbula derecha, mostrando el tendón del $A_{3}$ y fascículo $A_{w}$; fueron removidos los fascículos $A_{1}$ y $A_{2}$.

A

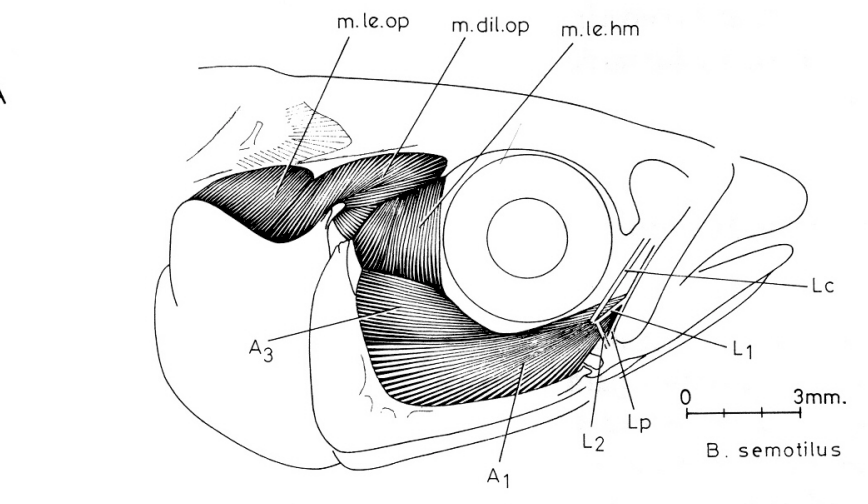

B
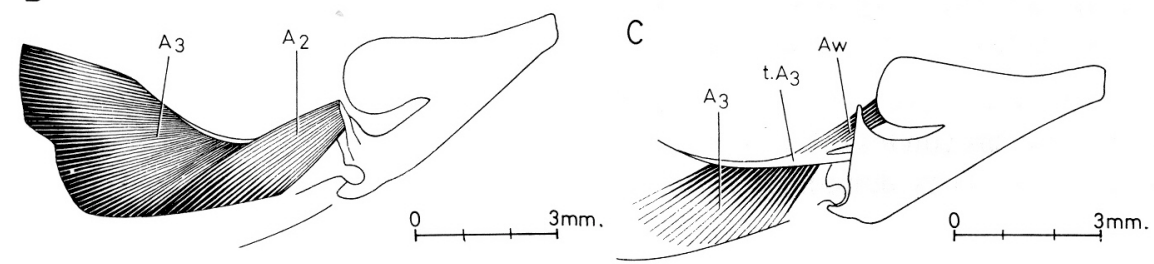

Figura 13. A) Vista lateral de los principales músculos relacionados con el mecanismo mandibular en Basilichtys semotilus. B) Vista lateroexterna de la mandíbula derecha, que muestra los fascículos $\mathrm{A}_{2}$ y $\mathrm{A}_{3}$ del músculo aductor mandibular; fue removido el fascículo $A_{1}$. C) Vista lateroexterna de la mandibula derecha, mostrando el tendón del $A_{3}$ y fascículo $A_{w}$; fueron removidos los fascículos $A_{1}$ y $A_{2}$. 
A

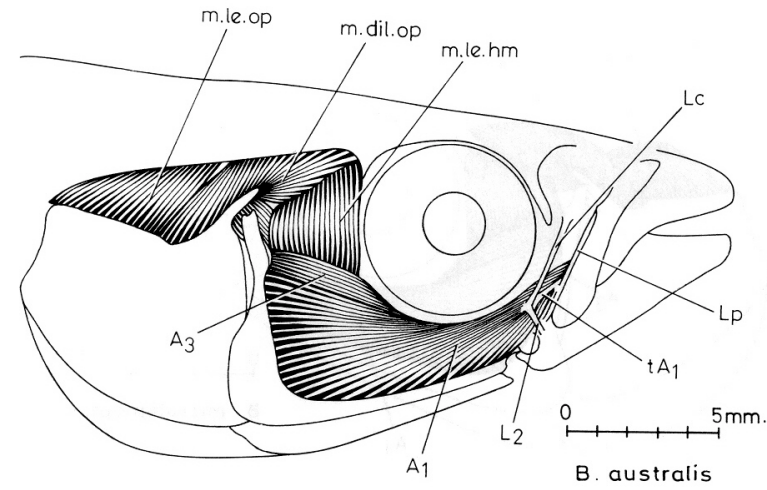

$\mathrm{B}$

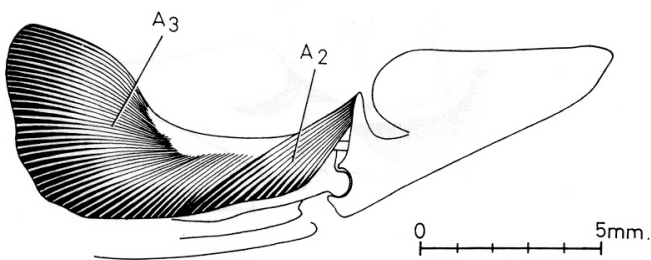

C

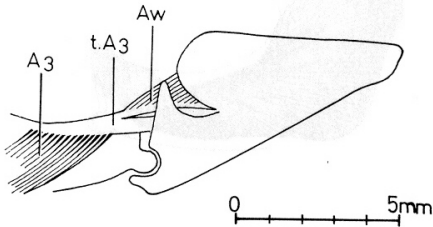

Figura 14. A) Vista lateral de los principales músculos que se relacionan con el mecanismo mandibular en Basilichtys australis. B) Vista lateroexterna de la mandíbula derecha, que muestra los fascículos $A_{2}$ y $A_{3}$ del músculo aductor mandibular; fue removido el fascículo $A_{1}$. C) Vista lateroexterna de la mandíbula derecha, mostrando el tendón del $\mathrm{A}_{3}$ y fascículo $\mathrm{A}_{\mathrm{w}}$; fueron removidos los fascículos $\mathrm{A}_{1}$ y $\mathrm{A}_{2}$.

tadura del borde del maxilar y se inserta en la superficie externa del articular-angular, cerca del extremo de su proceso dorsal (Figs. 18 a 20).

\section{Consideraciones funcionales de los distintos esquemas estructurales}

Dos tipos de actividades relacionadas con mecanismos de captura de presas han sido descritos para especies de los géneros Cauque, Austromenidia, Basilichthys y Odontesthes: protrusión premaxilar y mordida premaxilar (De la Hoz y Vial, 1988, 1994; De la Hoz, 1994a, 1994b; De la Hoz y Aldunate, 1994).

Las características de estos mecanismos están directamente relacionadas con los diseños estructurales de las piezas esqueléticas, músculos y ligamentos.

El grupo Cauque-Austromenidia, al que puede agregarse Odontesthes, presenta una gran capacidad de protrusión premaxilar, mientras que en el grupo de especies de Basilichthys ésta es muy reducida, aunque siempre presente. El análisis a través de

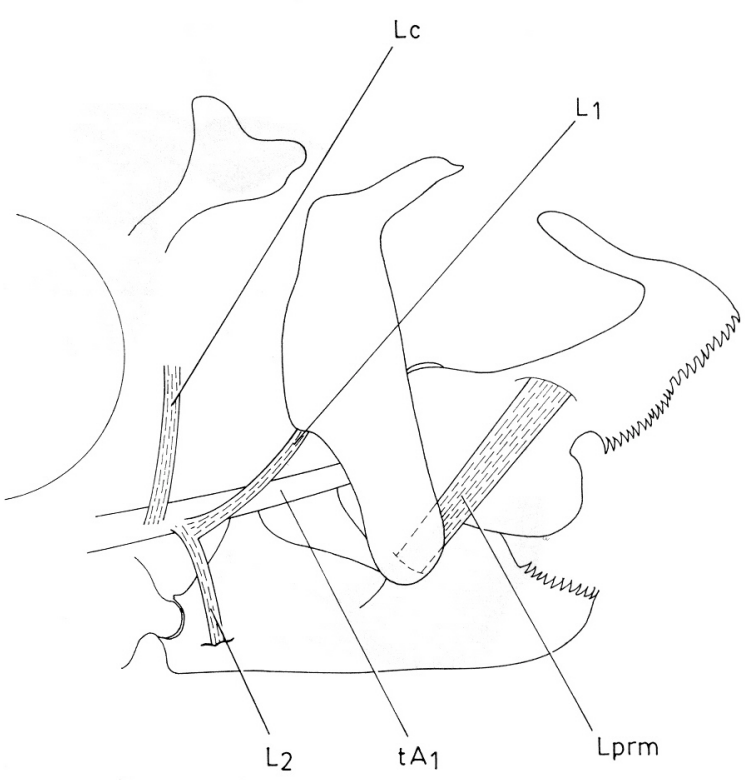

Figura 15. Esquema en vista lateral, del sistema tendinoso del fascículo $A_{1}$ del músculo aductor mandibular en Cauque mauleanum. 


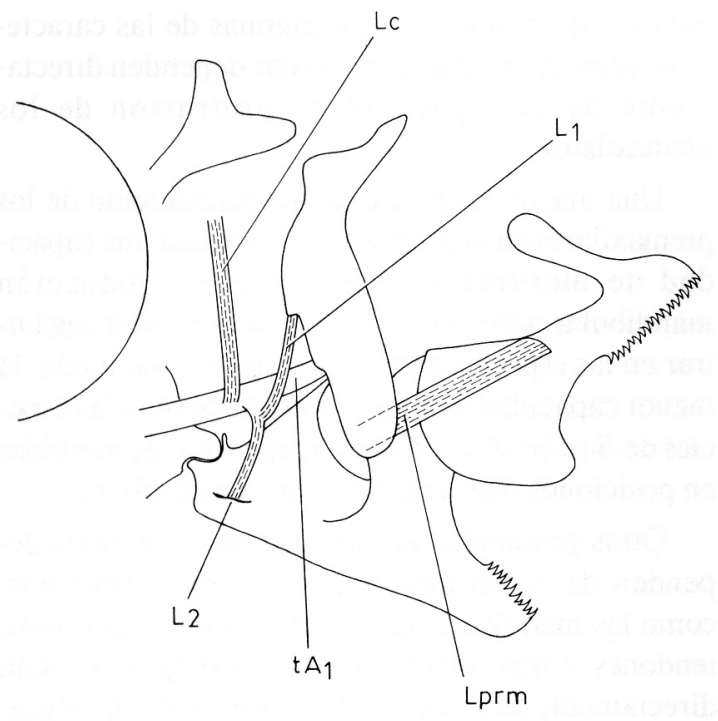

Figura 16. Esquema en vista lateral, del sistema tendinoso del fasciculo $A_{1}$ del músculo aductor mandibular en Cauque brevianalis.

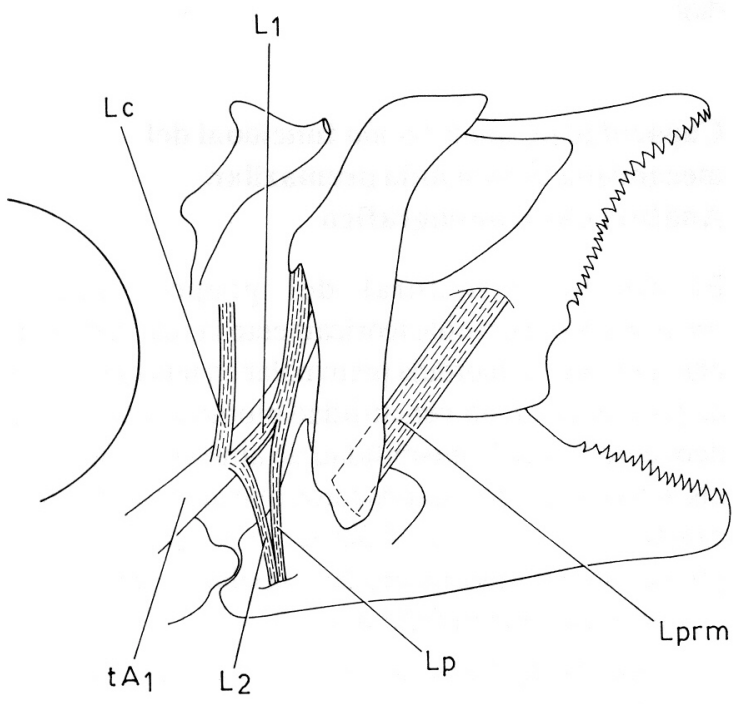

Figura 17. Esquema en vista lateral, del sistema tendinoso del fascículo $A_{\text {del }}$ músculo aductor mandibular en Austromenidia regia. modelos cinemáticos, realizados por los mismos autores anteriores, ha permitido constatar que una mayor capacidad de protrusión es consecuencia de un disefio distinto del sistema de ligamentos rostrales, además de las proporciones entre los bordes dorsales y longitud de la mandíbula.

El mecanismo de mordida premaxilar ha sido analizado independientemente en distintos aspectos, tales como magnitudes y velocidades de desplazamiento de premaxilares y mandíbulas, capacidades de mordida en posiciones relativas de aducción mandibular y protrusión premaxilar, y magnitudes de transmisión de fuerzas hacia el borde de mordida (De la Hoz, 1994a, 1994b; De la Hoz y Aldunate, 1994).

La mayor capacidad de mordida, en cuanto a magnitudes de desplazamiento, fuerza transmitida y potencialidad de morder en un mayor rango de posiciones, la poseen las especies de Cauque y Austromenidia, mientras que en Basilichthys estas características se encuentran bastante más restringidas.

Algunas de las cualidades funcionales conside. radas en este mecanismo de mordida premaxilar, están directamente asociadas a los mismos parámetros

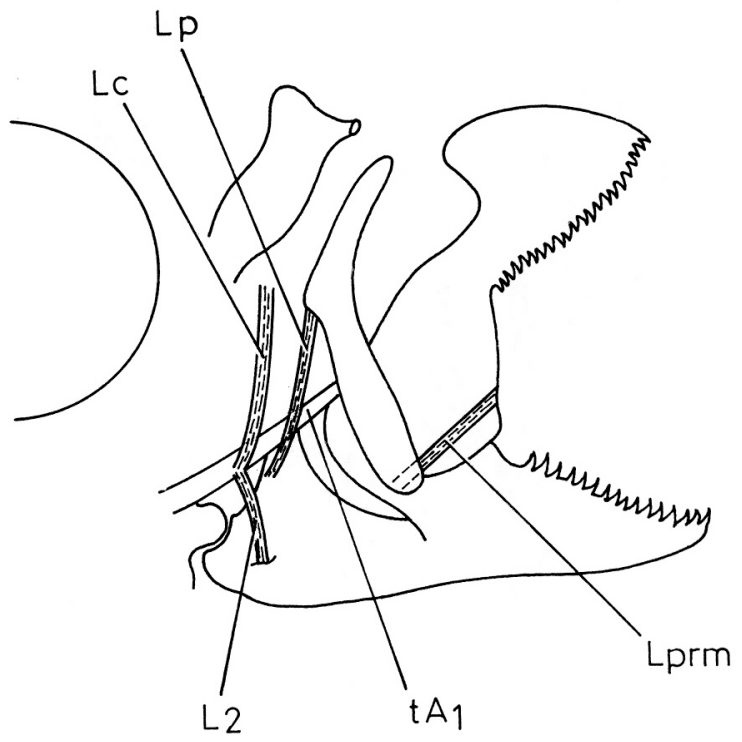

Figura 18. Esquema en vista lateral, del sistema tendinoso del fascículo $A_{1}$ del músculo aductor mandibular en Basilichtys microlepidotus. 


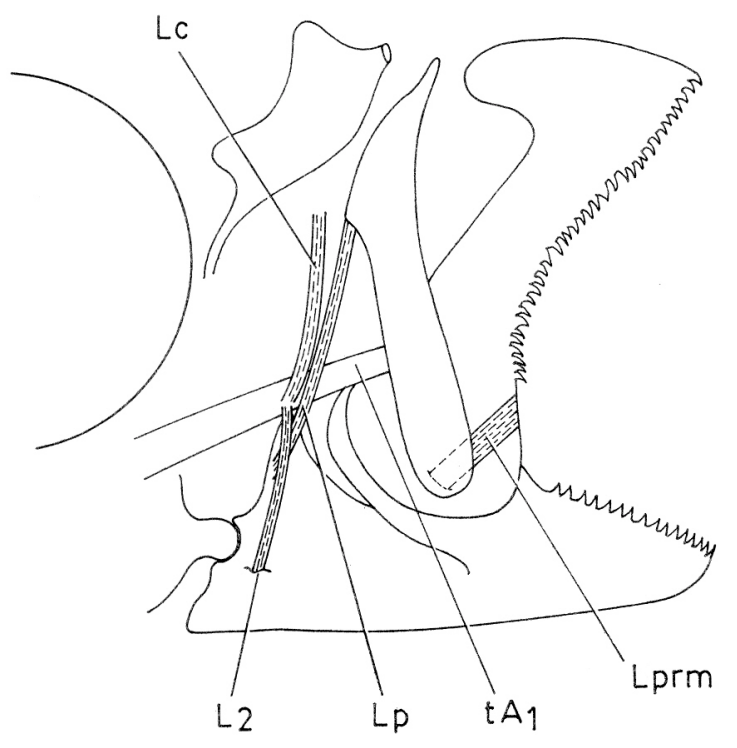

Figura 19. Esquema en vista lateral, del sistema tendinoso del fascículo $\mathrm{A}_{1}$ del músculo aductor mandibular en Basilichtys semotilus.

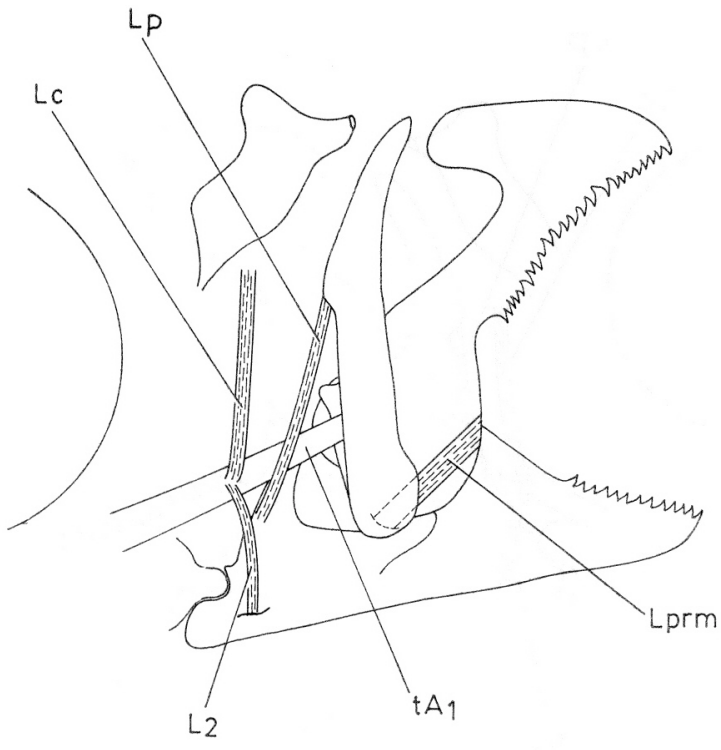

Figura 20. Esquema en vista lateral, del sistema tendinoso del fascículo $A_{1}$ del músculo aductor mandibular en Basilichtys australis. estructurales que controlan las características de la protrusión premaxilar.

Desde el punto de vista de la cinemática, es posible apreciar que ambos mecanismos están estrechamente relacionados, ya que algunas de las características de la mordida premaxilar dependen directamente de la capacidad de protrusión de los premaxilares.

Una mayor magnitud de desplazamiento de los premaxilares en la protrusión, determina una capacidad de mordida en posiciones de abducción mandibular mayores, como la que es posible encontrar en las especies de Cauque; del mismo modo, la menor capacidad de protrusión que poseen las especies de Basilichthys limita la realización de mordidas en posiciones más abducidas de la mandíbula.

Otras cualidades del mecanismo de mordida dependen de la configuración de otras estructuras, como las modificaciones en el diseño de músculos, tendones y ligamentos, que en principio no están directamente asociadas con la realización del mecanismo de protrusión premaxilar. En este sentido se entiende la aparición en el grupo Cauque Austromenidia de una conexión tendinosa adicional con el maxilar (L1), que pennite una mayor independencia de los movimientos del maxilar respecto de la mandíbula; la carencia de este ligamento en las especies de Basilichthys, restringe la capacidad de mordida, por la mantención del acoplamiento directo entre maxilar y mandibula a través del ligamento primordial.

\section{Capacidad de modulación funcional del mecanismo de mordida premaxilar. Análisis electromiográfico}

El diseño estructural del grupo CauqueAustromenidia permite teóricamente la realización de una actividad de mordida premaxilar en una gran gama de posiciones. Esta versatilidad biomecánica estaría dependiendo de la posibilidad de ajustar y coordinar las actividades de los músculos que accionan el mecanismo, en este caso el fascículo $A_{1}$ que mueve el premaxilar por intermedio del maxilar, y el fascículo $\mathrm{A}_{3}$ que acciona la mandíbula.

Análisis de datos electromiográficos obtenidos de los fascículos $\mathrm{A}_{1}$ y $\mathrm{A}_{3}$ del músculo aductor mandibular, coordinados con filmaciones, han pennitido verificar estas capacidades de modulación fun- 
cional del mecanismo de mordida premaxilar en Cauque brevianalis.

Se ha constatado la realización de distintos eventos en los que existe actividad mecánica de premaxilares y mandíbulas:

\section{a. Cierre bucal y retracción de la protrusión premaxilar sin mordida}

La Figura 21 muestra la actividad única del fascículo $\mathrm{A}_{3}$, durante la realización de esta actividad, sin participación del fascículo $A_{1}$.

El análisis de las imágenes indica que comenzando de una condición previa de boca abierta, en máxima protrusión (imagen 1), la contracción del fascículo $\mathrm{A}_{3}$ provoca la subida mandibular y, a través de ésta, se consigue la retracción total del sistema (imágenes 2 a 4). Esta actividad se ha observado durante la captura de alimento sólo por succión de partículas o presas libres, sin participación del mecanismo de mordida.

\section{b. Captura de presas con mordida premaxilar}

La condición para que exista mordida, es que tanto la mandíbula como el premaxilar estén ejerciendo fuerzas mutuamente el uno contra el otro.

Análisis de los datos obtenidos en numerosos eventos de mordida, han permitido constatar una gran variedad en la coordinación y duración de las actividades entre ambos fascículos musculares.

Una sincronía en el comienzo y término de la actividad muscular de los fascículos $\mathrm{A}_{1}$ y $\mathrm{A}_{3}$ (Fig. 22), determina la realización de una mordida manteniendo un grado de protrusión premaxilar, que no alcanza al máximo posible (imágenes 2 a 4).

El término de la actividad muscular del fascículo $\mathrm{A}_{3}$ al mismo tiempo que el $\mathrm{A}_{1}$, hace que la mandíbula detenga su ascenso de tal manera que posibilita la realización de repetidas acciones de mordida sin retracción del sistema premaxilar.

En algunos de los eventos de mordida observados, la actividad del fascículo $\mathrm{A}_{1}$ comienza antes que la del $\mathrm{A}_{3}$ (Fig. 23), lo que determina que la posición de la mordida se localice más ventralmente que en el caso de la figura 22. La prolongación de la contracción del $\mathrm{A}_{3}$, una vez finalizada la acción de mordida, provoca la retracción del sistema (Fig. 23, imagen 4).

\section{c. Protrusión premaxilar con boca cerrada}

Asociado a la actividad de devolución del alimento a través de la apertura bucal («spitting») se ha obser- vado un mecanismo de protrusión premaxilar manteniendo la boca cerrada a partir de una posición retraída del sistema (Fig. 24). En relación con esta actividad sólo se ha detectado contracción del fascículo Al, durante el movimiento de abducción mandibular (imágenes 3 y 4).

Dado que en algunas ocasiones se observó que esta actividad era realizada sin que hubiera devolución del alimento, probablemente este mecanismo de protrusión premaxilar con boca cerrada esté relacionado con el requerimiento de aumentar el volumen de la región anterior de la cavidad bucal, para desplazar las partículas desde la zona branquial a una posición más anterior, dando la posibilidad de mantener y reingerir la presa, o bien, expulsarlas a través de la boca; en ambos casos, los opérculos se mantienen abiertos durante la protrusión, indicando el ingreso de agua a través de ellos. Un mecanismo similar ha sido descrito para Cyprinus carpio, en donde también existe una protrusión premaxilar manteniendo la boca cerrada (Ballintijn et al., 1972; Sibbing, 1982; Sibbing et al., 1986).

Para la comparación de las potencialida:des de versatilidad funcional del esquema estructural de Basilichthys, se realizaron filmaciones y electromiografía en Basilichthys microlepidotus.

Todas las observaciones realizadas en especímenes de esta especie coincidieron en la presencia de un solo patrón de actividad muscular, con partipación simultánea de ambos fascículos $\mathrm{A}_{1}$ y $\mathrm{A}_{3}$ del aductor mandibular (Fig. 25). Normalmente el comienzo de las contracciones es sincrónico; sin embargo, el término de ellas puede ser simultáneo (imagen 4) o existir una prolongación de la actividad del fascículo $\mathrm{A}_{3}$ (imagen 5). Esta última circunstancia permite la retracción de la protrusión premaxilar.

La única variación encontrada se refiere a los tiempos de contracción muscular, dependiendo ello del tipo de actividad que se esté realizando: los mayores tiempos de actividad muscular fueron observados durante la mantención de la mordida, junto a una acción de tirar del alimento con bruscos movimientos laterales de la cabeza.

Liem $(1978,1979,1980)$ introduce el concepto de modulación en morfología funcional, en sus estudios sobre las bases funcionales de la versatilidad trófica de los Cichlidae; ello se refiere a la habilidad para modificar los esquemas de actividad neuromuscular ajustándolos a situaciones específi- 

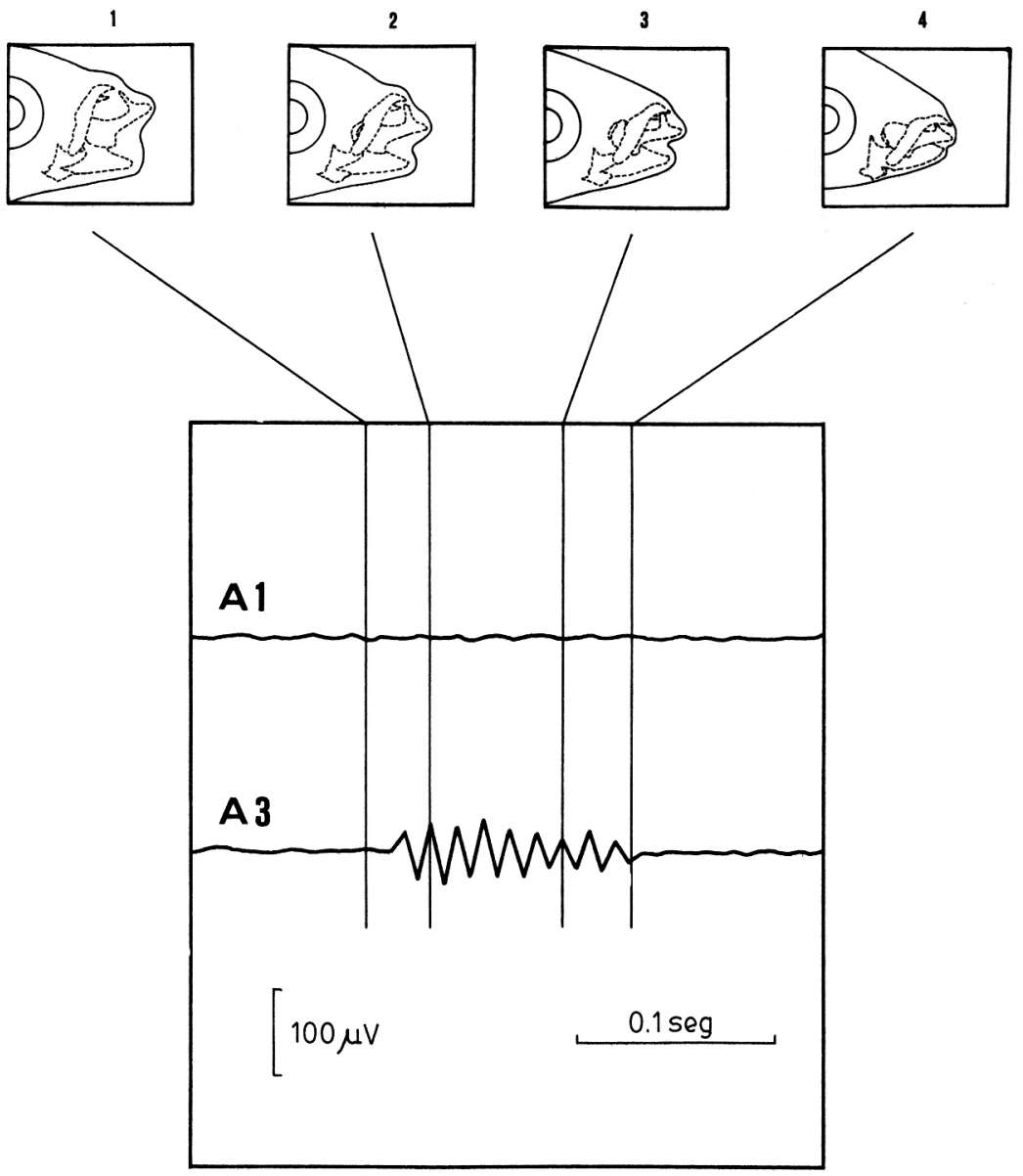

Figura 21. Esquema representativo de la actividad de los fascículos $A_{1}$ y $A_{3}$ del aductor mandibular en Cauque brevianalis, durante el mecanismo de cierre mandibular con retracción premaxilar. Las figuras superiores corresponden a imágenes de video a las que se le han superpuesto las piezas bucales. El gráfico corresponde a las señales electromiográficas de los fascículos musculares.

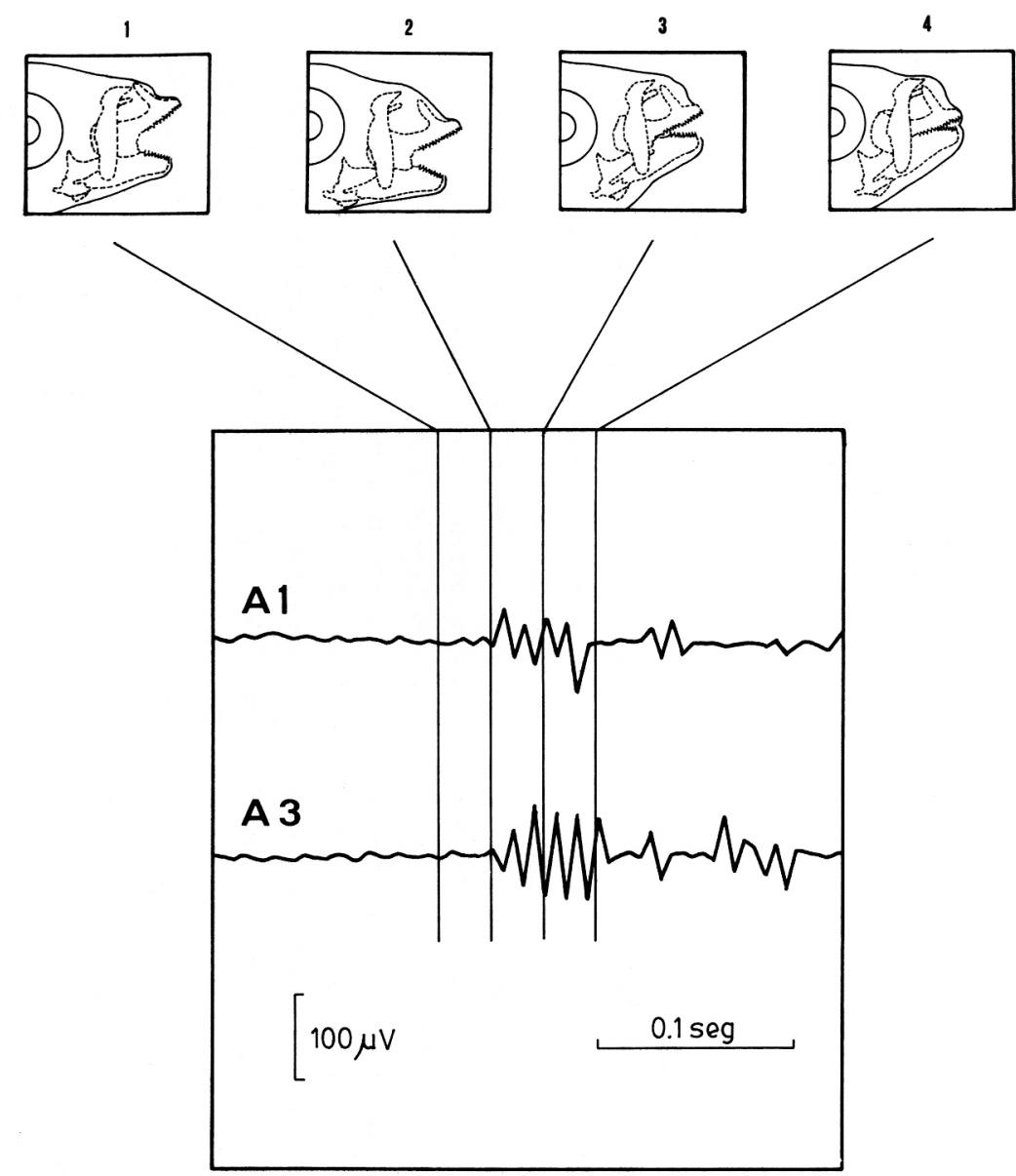

Figura 22. Esquema representativo de la actividad de los fascículos $A_{1}$ y $\mathrm{A}_{3}$ del aductor mandibular en Cauque brevianalis, durante el mecanismo de mordida premaxilar. 

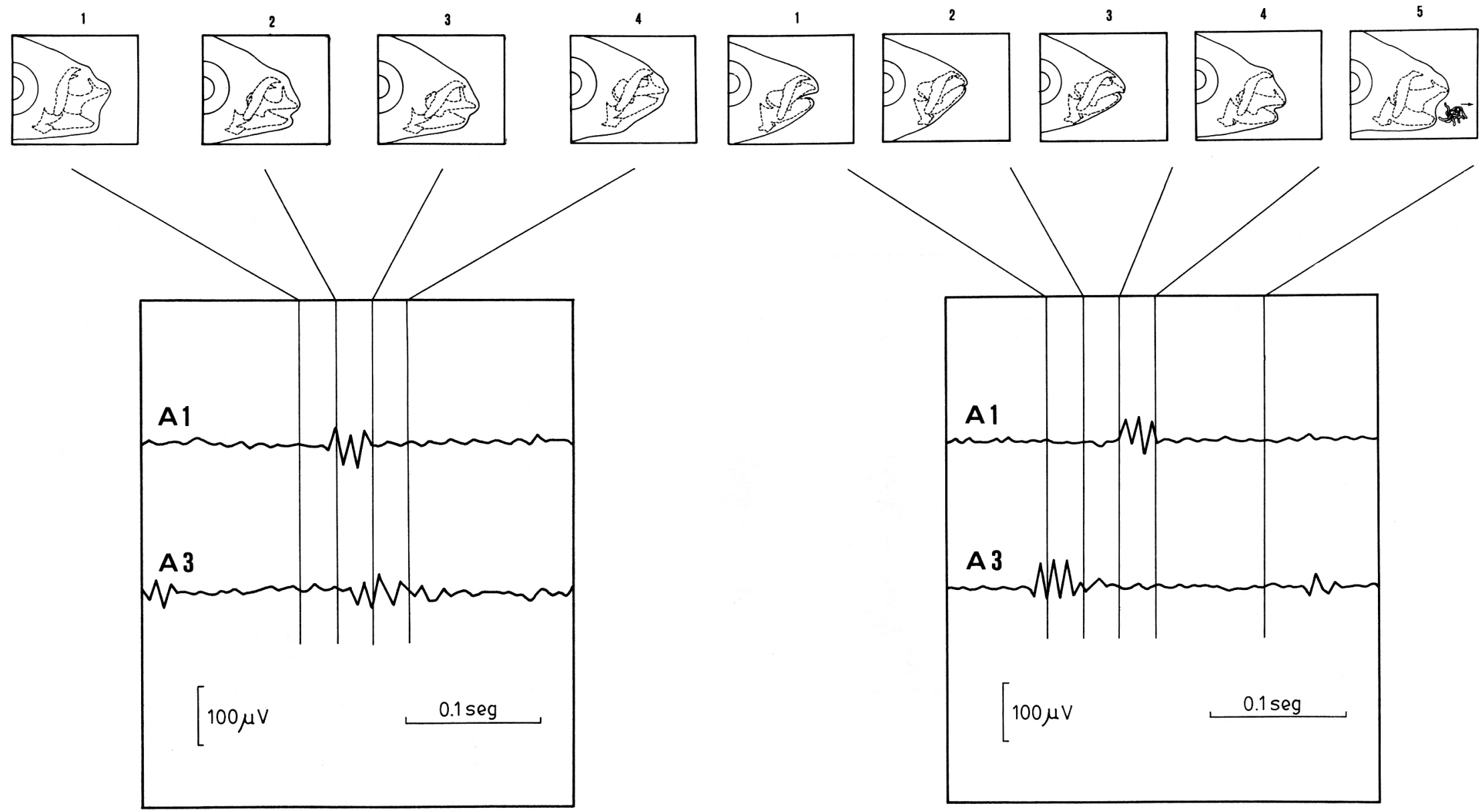

Figura 23. Esquema representativo de la actividad de los fascículos $A_{1}$ y $A_{3}$ del aductor mandibular en Cauque brevianalis, durante el mecanismo de mordida premaxilar en posición más ventral.

Figura 24. Esquema representativo de la actividad de los fasciculos $A_{1} y$ $A_{3}$ del aductor mandibular en Cauque brevianalis, durante el mecanismo de devolución de alimento (spitting). 


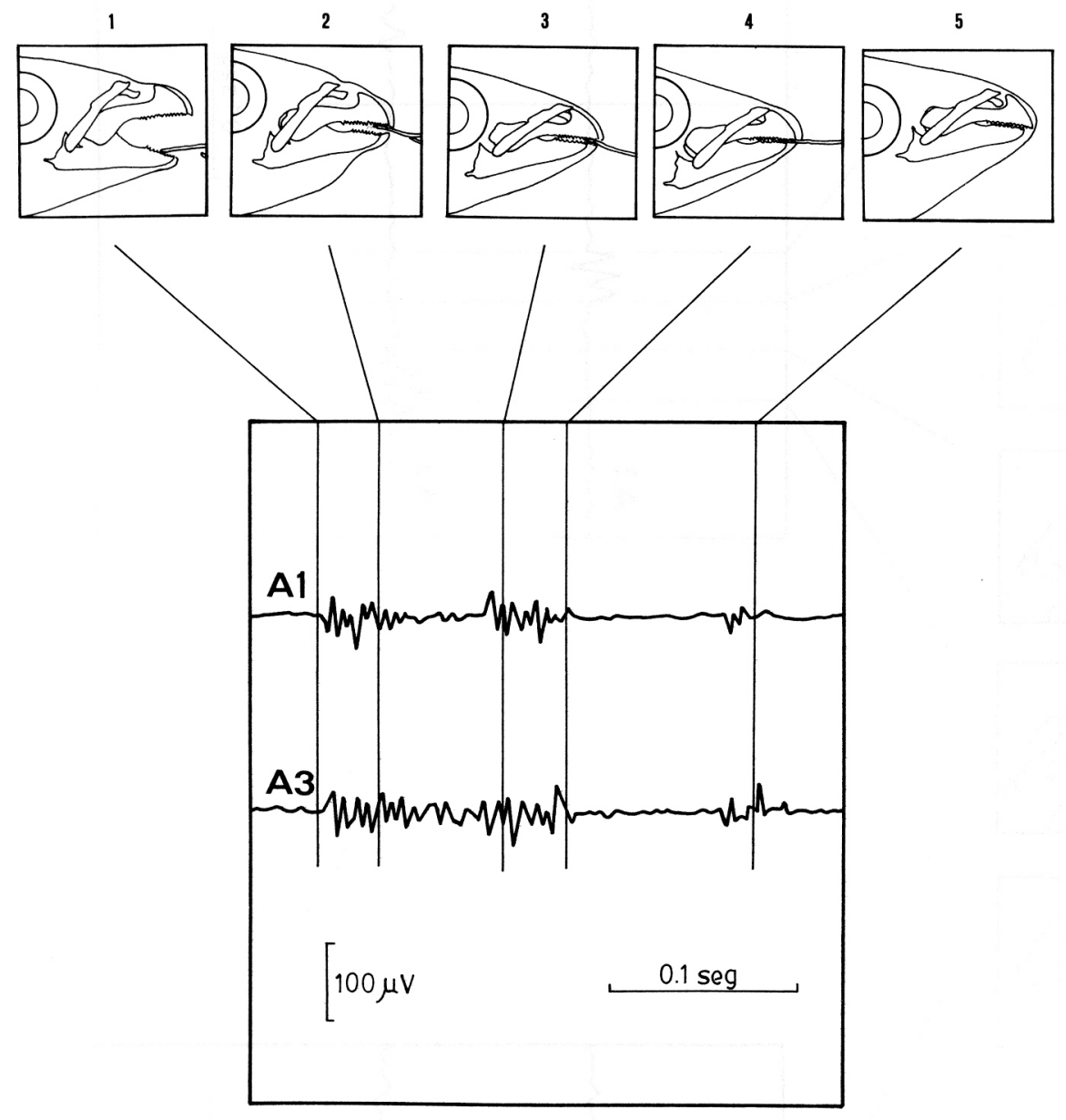

Figura 25. Esquema representativo de la actividad de los fascículos $\mathrm{A}_{1}$ y $\mathrm{A}_{3}$ del aductor mandibular en Basilichtys microlepidotus, durante el mecanismo de captura de presa mediante mordida.

cas de alimentación. Sin embargo, dado que una versatilidad trófica puede depender tanto de la habilidad para elegir entre varios esquemas especializados, como del uso flexible de un solo programa de alimentación, Chu (1989) restringe el término modulación a la selección de un esquema cinemático y neuromuscular como un todo, llamando plasticidad a la habilidad para modificar un esquema dado como respuesta a parámetros cambiantes de situaciones individuales de alimentación.

Las especies pertenecientes al grupo Саиque-
Austromenidia presentan, en este sentido, una capacidad de modulación, seleccionando ya sea un simple mecanismo de protrusión premaxilar, que habilita para capturar presas mediante succión, o bien, utilizando el mecanismo de mordida premaxilar para aprehensión directa de las presas. Al mismo tiempo, estas especies manifiestan un alto grado de plasticidad, dentro del mecanismo de mordida premaxilar, ajustándolo a las características y condiciones de las presas. Observaciones realizadas en varios eventos de alimentación utilizando sólo protrusión y succión, 
demuestran que este esquema es bastante conservador, realizándose siempre de la misma manera.

Por otro lado, las especies del grupo Basilichthys presentan una carencia de modulación, mostrando un esquema bastante estereotipado en sus mecanismos de captura de alimento, que incluye siempre una apertura bucal con una leve protrusión, seguida de un cierre bucal en el cual participa el premaxilar. Sin embargo, Basilichthys posee una cierta capacidad de modificar este esquema de modo de ajustado a situaciones diferentes de las presas, variando la duración de las actividades musculares.

Durante la evolución de los distintos mecanismos de protrusión premaxilar, varios grupos de Acanthopterygii han desarrollado un sistema de bloqueo de los premaxilares, permitiendo la posibilidad de una mordida firme y precisa con la mandíbula en varios estados de protrusión premaxilar (Alexander, 1966,1967; Gosline, 1980, 1981; Liem, 1979; Liemy Osse, 1975). En todos los casos descritos, es el maxilar el que ejecuta mecánicamente este bloqueo, impidiendo que el premaxilar sea retraído, a través del contacto directo entre el proceso anterior de la cabeza maxilar y el proceso articular y/o proceso ascendente del premaxilar. En algunos casos, en formas con boca grande, la acción de bloqueo se produce por la rotación del maxilar en su eje, normalmente producida por la expansión lateral de la boca, mientras que en formas de boca pequeña, la fijación se produciría principalmente por la contracción de la sección «maxillaris» del aductor mandibular (Alexander, 1967; Gosline, 1981).

Se ha descrito una gran variabilidad de movimientos de mandíbulas y premaxilares para diferentes especies de Cichlidae, cuyos electromiogramas muestran diferencias en la sincronía y duración de la actividad muscular (Liem y Osse, 1975). Los Cichlidae, en general, parecen poder regular de manera muy precisa la velocidad y grado de la protrusión mediante la variación de la sincronía y modulando el grado de contracción del fascículo Al del músculo aductor mandibular y de los músculos antagonistas.

Similares variaciones en la actividad muscular se han encontrado en Characoidei (Lauder, 1981), Cyprinidae (Ballintijn et al., 1972) y Percidae (Elshould-Oldenhave y Osse,1976).

A diferencia de los grupos anteriores, algunos Atherinopsinae sudamericanos han desarrollado un sistema de protrusión y mordida premaxilar totalmen- te distinta, caracterizado por la presencia de una unión ligamentosa entre mandíbula y premaxilar, una pérdida de relación directa entre los extremos proximales de maxilar y premaxilar, y por la conexión ligamentosa distal entre estos huesos (De la Hoz y Vial, 1988, 1994).

La plasticidad manifestada por las especies de Cauque y Austromenidia para ajustar la posición de mordida y la magnitud de protrusión premaxilar, está basada en la capacidad de modificar la sincronización en la actividad de los fascículos $\mathrm{A}_{1}$ y $\mathrm{A}_{3}$ del músculo aductor mandibular.

\section{AGRADECIMIENTOS}

Este estudio fue financiado a través del Proyecto FONDECYT 721/92. Los autores agradecen a la Sra. Carmen Tobar, Dibujante Científico del Instituto de Biología de la Universidad Católica de Valparaíso, por la confección de las figuras.

\section{REFERENCIAS BIBLIOGRAFICAS}

ALEXANDER, R. McN. 1966. The functions and mechanisms of the protrusible upper jaws of two species of cyprinid fish. J. Zool., (London), 149: 288-296.

ALEXANDER, R. McN. 1967. The functions and mechanisms of the protrusible upper jaws of some acanthopterygian fish. J. Zool., (London), 151: 43-64.

ANKER, G. Ch. 1978. The morphology of the head muscles of a generalized Haplochromis species: H. elegans Trewavas 1933 (pisces, Cichlidae). Neth. J. Zool., 28: 234-271.

BALLINTIJN; C.M., A. VAN DEN BURG AND B.P. EGBERINK. 1972. An electromyographic study of the adductor mandibulae complex of a freeswimming carp (Cyprinus carpio L.) during feeding. J. Exp. Biol., 57: 261-283.

BAREL, C.D.N. 1983. Towards a constructional morphology of cichlid fishes (Teleostei, Perciformes). Neth. J. Zool., 33: 357-424. 
BAREL, C.D.N. 1984. Form-re1ations in the context of constructional morphology: the eye and suspensorium of lacustrine Cichlidae (pisces, Teleostei). Neth. J. Zool., 34: 439-502.

CHU, Ch. 1989. Functional design and prey capture dynamics in an ecologically generalized surfperch (Embiotocidae), J. Zool. (London), 217: 417-440.

DE LA HOZ, E. 1994a. Aspectos cinemáticos del mecanismo de mordida premaxilar en los géneros Cauque, Basilichthys y Austromenidia (Teleostei, Atherinopsinae). Invest. Mar. Valparaíso, 22: 31-37.

DE LA HOZ, E. 1994b. El mecanismo de mordida premaxilar en Atherinopsinae: aspectos estructurales relacionados con la transmisión de fuerzas. Rev. Chil. Hist. Nat. (en prensa).

DE LA HOZ, E. y R. ALDUNATE. 1994. Variaciones del complejo tendinoso del fascículo $\mathrm{A}_{1}$ del músculo aductor mandibular y sus consecuencias en el mecanismo de mordida premaxilar en Cauque, Austromenidia y Basilichthys (Atherinifonnes, Atherinopsinae). Rev. Biol. Mar. (en prensa).

DE LA HOZ, E. y J. VIAL. 1988. Potencialidades mecánicas del sistema de protracción premaxilar de Austromenidia regia (Teleostei, Atherinidae). Rev. Chil. Hist. Nat., 61: 163-176.

DE LA HOZ, E. y J. VIAL. 1994. Diseño estructural bucal en Atherinopsinae sudamericanos (Teleostei, Atherinidae): modelo biocinemático de mecanismos de alimentación. Rev. Chil. Hist. Nat., 67: 35-47.

DINGERKUS, G. and L.D. UHLER. 1977. Enzyme clearing of alcian blue stained whole small vertebrates for demonstration of cartilage. Stain Technology, 52: 229-232.

DULLEMEIJER, P. 1974. Concepts and approaches in animal morphology. V. Gorkum, Assen, The Netherlands.

DULLEMEIJER, P. and C.D.N. BAREL. 1977. Functional morphology and evolution. In: «Major patterns in vertebrate evolution». Hecht M, PC Goody \& BM Heght (Eds.). NATO Advanced Study Institute Series A, 14: 83-117. Plenum Press, N.Y.
ELSHOULD-OLDENHAVE, M.J.W. and J.W.M. OSSE. 1976. Functional morphology of the feeding system in the ruff Gymnocephalus cernua (L. 1758) (Teleostei, Percidae). J. Morph., 150: 399422.

GOSLINE, W.A. 1980. The evolution of some structural systems with reference to the interrelationships of modern lower teleostean fish groups. Jap. J. Ichthyol., 27: 1-28.

GOSLINE, W.A. 1981. Theevolution of the premaxillary protrusion system in some teleostean fish groups. J. Morph., 193: 1-10.

LAUDER, G.V. 1981. Instraspecific functional repertoires in the feeding mechanism of the Characoid fishes Lebiasina, Hoplias and Chalceus. Copeia (1): 154-168.

LAUDER, G.V. and K.F. LIEM. 1981. Prey capture by Luciocephalus pulcher: implications for models of jaw protrusion in teleost fishes. Env. Biol. Fish., 6: 257-268.

LIEM, K.F. 1978. Modulatory multiplicity in the functional repertoire of the feeding mechanism in cichlid fishes. I. Piscivores. J. Morph., 158: 323-360.

LIEM, K.F. 1979. Modulatory multiplicity in the feeding mechanism in cichlid fishes, as exemplified by the invertebrate pickers of Lake Tanganyika. J. Zool. (London), 189: 93-125.

LIEM, K.F. 1980. Adaptive significance of intra-and interspecific differences in the feeding repertoires of cichlid fishes. Amer. Zool., 20: 295-314.

LIEM, K.F. and J.W.M. OSSE. 1975. Biological versatillity, evolution, and food resource exploitation in African cichlid fishes. Amer. Zool., 15: 427-454.

OSSE, J.W.M. 1969. Functional morphology of the head of the perch (Perca fluviatilis L.): an electromyographic study. Neth. J. Zool., 19: 289392.

OTTEN, E. 1982. The development of a mouthopening mechanism in a generalized Haplochromis species: H. elegans Trewavas 1933 (Pisces, Cichlidae). Neth. J. Zool., 32: 31-48. 
SIBBING, F.A. 1982. Pharyngeal mastication and food transport in the carp (Cyprinus carpio L.): a cineradiographic and electromyographic study. J. Morph., 172: 223-258.
SIBBING, F. A., J.W.M. OSSE and A. TERLOUW. 1986. Food handling in the carp (Cyprinus carpio): its movement patterns, mechanisms and limitations. J. Zool. (London), 210: 161-203.

Recibido el 21 de marzo de 1994.

Aceptado el 25 de octubre de 1994. 